\title{
Experimental Investigation of Water Migration Characteristics for Saline Soil
}

\author{
Xudong Zhang ${ }^{1}$, Shouwei Liu², Qing Wang ${ }^{1 *}$, Gang Wang ${ }^{3}$, Yufeng Liu', \\ Wei Peng ${ }^{1}$, Xinchuan $\mathrm{Xu}^{2}$, Yaowu Liu ${ }^{1}$ \\ ${ }^{1}$ College of Construction Engineering, Jilin University \\ ${ }^{2}$ Water Conservancy and Hydropower Survey and Design Institute of Jilin Province, Changchun \\ ${ }^{3}$ School of Geomatics\& Prospecting Engineering, Jilin Jianzhu University
}

Received: 25 September 2017

Accepted: 28 February 2018

\begin{abstract}
Soil in western Jilin, China has the properties of a saline soil, seasonal frozen soil, and a dispersive soil, in which the freezing process can induce many engineering and environmental problems, including soil secondary salinization and frost heave. During the freezing process, water, heat, stress, and even solute interact with each other. Water migration plays an important role in this process. In this paper, a sampling point in Nong'an, western Jilin was selected for soil collection and experimental tests. The experiment included two tests: the capillary water test and a water migration test subjected to freezing. The results showed that the height of capillary water is low, while the water migrates obviously after the process of freezing in different conditions. The results indicate that the bound water film hinders the capillary pores, which can impair the matric potential. During the freezing process, the temperature potential and gravitational potential can drive the water to migrate through the bound water film. For the soil in western Jilin, temperature potential plays a decisive role in water migration, but gravitational potential and matric potential have a minor effects.
\end{abstract}

Keywords: carbonate-saline soil, soil water potential, bound water, water migration

\section{Introduction}

Western Jilin Province, located in the Song'nen Plain, China, is one of the typical soda alkali-saline soil distribution areas of China. With the passage of time, the area of salinized ground has increased, and there is a greater degree of salinization. The salinization is considered to be related to water migration and is affected by temperature [1-3]. Two general investigations

*e-mail: wangqing@jlu.edu.cn for saline soil area in Jilin Provinces were carried out in the late 1950s and 1980s [4]. In approximately three decades, the area of saline soil in Jilin increased from $1.6 \times 10^{6} \mathrm{hm}^{2}$ to $2.3 \times 10^{6} \mathrm{hm}^{2}[5,6]$. Between 1980 and 2000 , the area of saline-alkali soil and the degree of salinization increased; however, the area of slight saline-alkali soil decreased from $69.8 \%$ to $9.5 \%$. The area of moderate saline-alkali soil increased from $24 \%$ to $83 \%$, and the area of severe saline-alkali soil increased from $6.2 \%$ to $7.5 \%$ [7]. The ecological environment in this area is very fragile. The degree of salinization was aggravated, as shown in Fig. 1. 


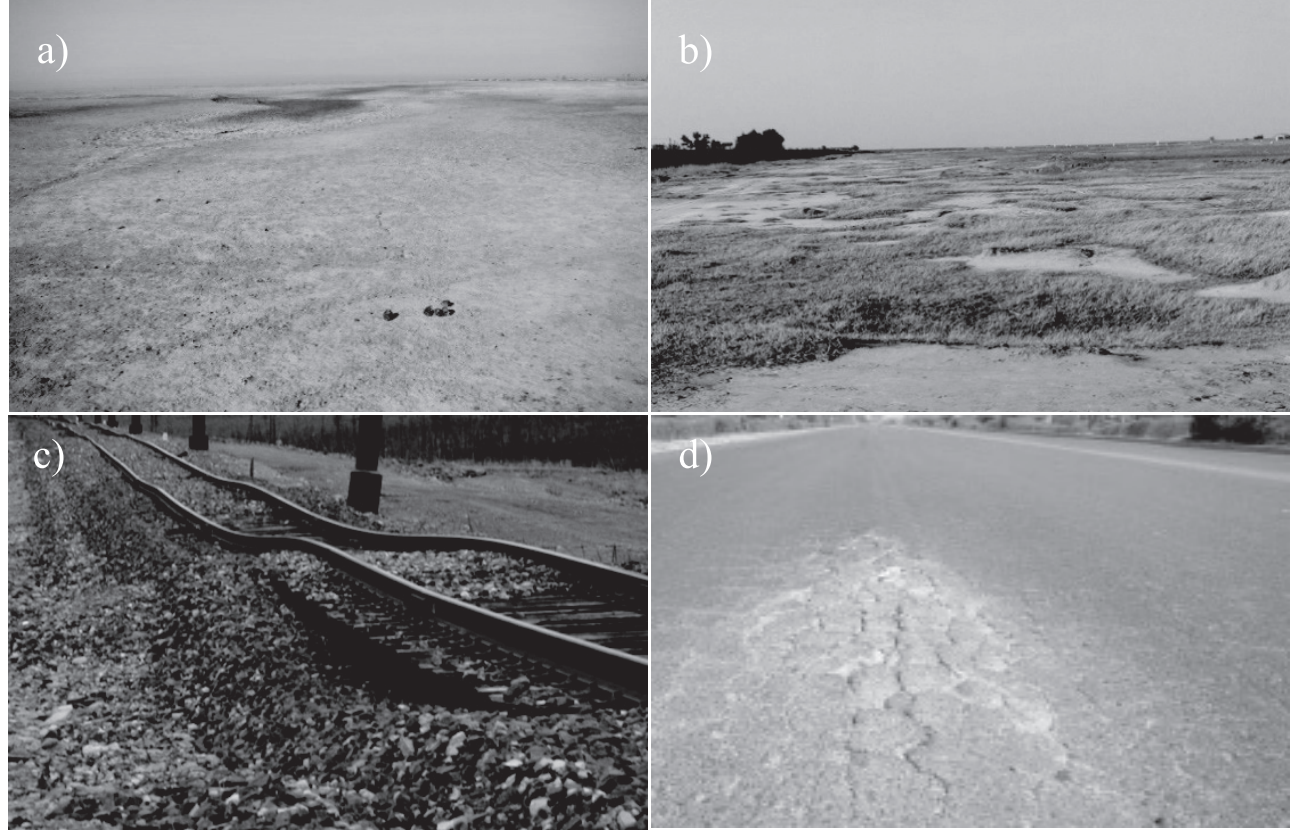

Fig. 1. Geological disasters related to water migration in western Jilin: a) Salinization ground, b) Salinization ground, c) Frost heave, d) Salt expansion.

Salinization harms local agriculture and may decrease crop output $[8,9]$. Thus, the study of the saline soil in this area is an important research issue.

Previous studies have indicated that soil salinization has a close relationship with water migration $[2,10]$. The northeastern region of China has a temperate continental climate; thus, western Jilin is a typical seasonal frozensoil distribution area. It has severe cold winters and torrid summers. The spring and autumn are windy and dry due to the monsoon climate of the medium latitudes. In the summer, moisture migrates upward to the surface of the soil under the strong effect of evaporation [10]. Induced by the moisture, salt is transported and easily accumulates on the surface, and salinity forms in the soil $[10,11]$. In the winter, the freezing front slowly moves from the surface downward as the air temperature decreases. The water in the soil constantly migrates up to the freezing front $[2,12,13]$. During this process, salt is dissolved in the water and is transported upward. The following spring, the salinity gathers once more on the surface due to evaporation. As a result, salinization becomes more and more concentrated. The saline soil has salt expansion, corrosion, and many other environmental and engineering properties. In addition, under the freeze-thaw environment, the interactions of the temperature field, water field, and stress field may contribute to the complex hydrodynamic coupling system, leading to water migration and frost heave [14]. Due to the frost heave, some damage to infrastructure engineering projects may result, such as salt expansion and frost heave of the highways and different settlement of subgrades, as shown in Fig. 1. Soil salinization and the engineering damage in western Jilin harms regional agricultural production and restricts economic development. Therefore, to control the increasing salinization trend of soils and reduce the harm to engineering projects, it is necessary to investigate the characteristics of the saline-alkali soil in western Jilin. For the purpose of systematic study of the saline soils in Jilin, this study can provide the theoretical basis and practical significance for studying the water migration characteristics of the soil in this study area.

This study on water migration in the soil can be divided into field monitoring and an indoor experimental simulation. The indoor experimental simulation consists of the capillary water rise test under natural conditions and the water migration test subject to freezing. The freezing test includes an open system and a closed system. The open system is an experimental condition in which the soil is subjected to freezing with a water supplement connected to the soil column at the bottom, while in the closed system the experiment is carried out without any water supplement. The site test and indoor experiments were developed [15] in previous studies, and the characteristics were summarized. Some scholars have also focused on unsaturated freezing soils. Zhou [16] proposed a new method that included an imaginary pump to investigate the water migration characteristics of unsaturated soil. In addition to the freezing conditions, the evaporation processes also include a process of water migration. To figure out this process, some researchers also investigated the interactions among the thermal, suction, and osmotic gradients during evaporation for a salty soil. The results indicated that the evaporation process is controlled by heat flow and is limited by salinity and moisture fluxes [17]. Basically, due to the strong effects on engineering 


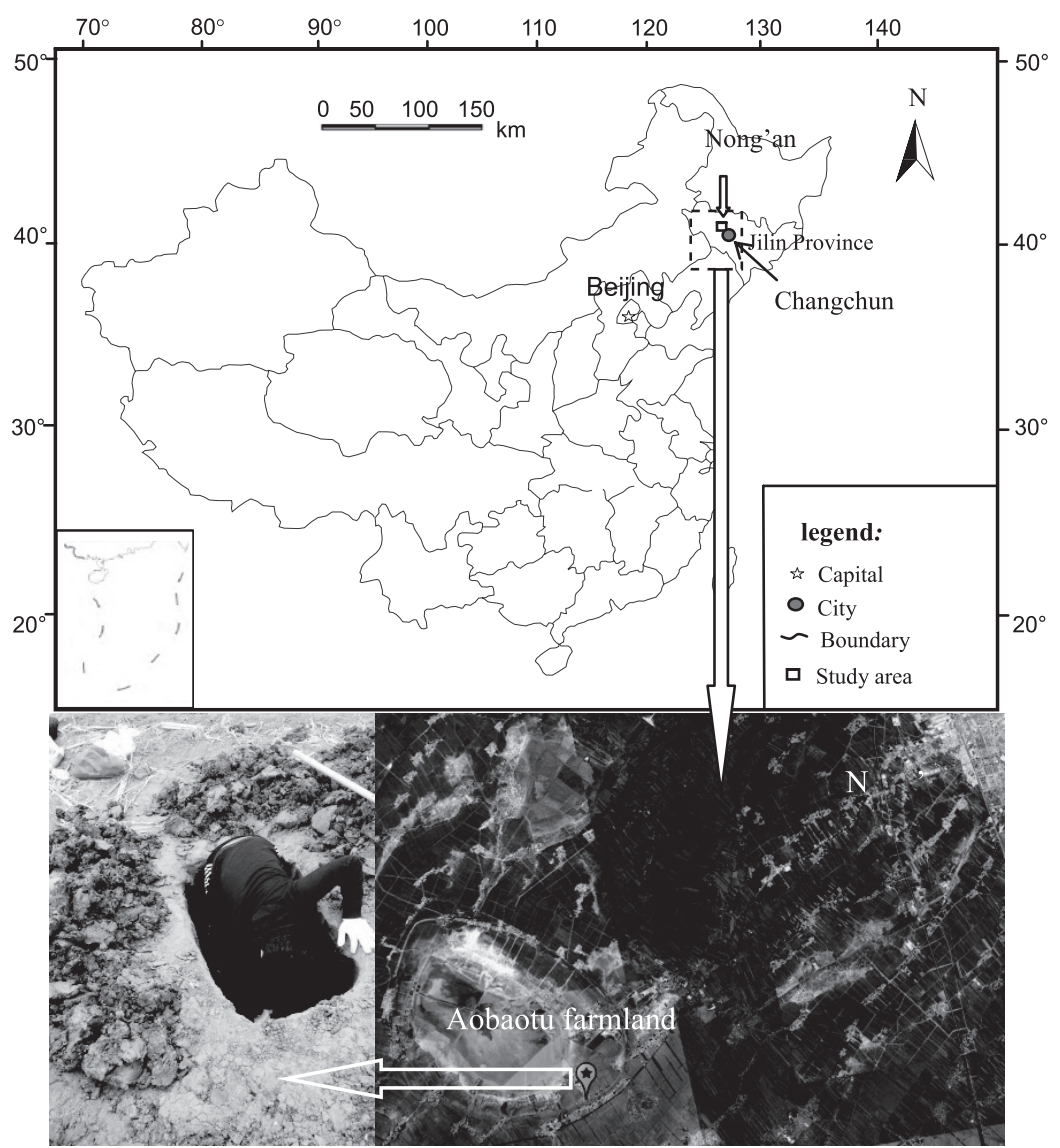

Fig. 2. Position of the sampling point.

and agriculture, many researchers also extended studies from different viewpoints to study the water migration properties, such as groundwater table depths on different conditions, including freeze-thaw and arid climates [18, 19]. For the soil in western Jilin, some scholars also carried out experiments to study the properties of saline soils. Studying the microstructure of frozen soil in Changchun, Li [20] developed chemical and mechanical tests; the results showed that the high proportion of clay particles, the high mineral content, and the high cation exchange capacity are beneficial to the formation of water film. Most of the pore sizes are less than $5 \mu \mathrm{m}$, which is favourable for water migration. In the water and salt transfer test in which the soil was subjected to freezing in Da'an, western Jilin, Wang [21] explained that the effect of water and salt migration results from the temperature gradient and the concentration gradient. Zhao [22] studied the influence of a single factor on water migration by changing the initial water content or temperature mode. Cai [23] studied the effect of tortuosity on the capillary imbibition in porous media. Zhao [24] modelled the process of coupled water and heat for the soil in freezing and thawing conditions. Robert [25] carried out experiments to study salt crystallization in the process of brine percolating upward and discussed the potential damage to masonry, foundations, and roads. However, only a fraction of the studies concerned the water migration characteristics and soilwater potential of the soil in western Jilin.

The present study investigates the characteristics of water migration for the saline soil in Western Jilin and provides a mechanism discussion, which involves the driving force of water migration during the freezing process. Combined with previous studies [26, 27], the typical areas where saline soil is distributed were selected for study. In this paper, the sampling point is located near the Aobaotu farmland in Nong'an, western Jilin (Fig. 2).

\section{Materials and Methods}

The soil in the experiment was collected from a depth of $40 \mathrm{~cm}$. According to the "Specification of soil test (SL237-1999)", the particle size distribution, physical properties, and the chemical components were tested. The basic physicochemical properties are listed in Table 1. The experimental soil in the study has a high content of clay particles and is considered to be silty clay according to the rules of DT-92. On the basis of the Code for the design of building foundations (GB50007-2002), it is recognized as clayey from the index of plasticity $I_{p}$. In summary, the soil that we studied has a high content of clay particles and high content of salt, in which the content of sodium $\left(\mathrm{Na}^{+}\right)$ 
Table 1. Basic physicochemical properties of the studied soil.

\begin{tabular}{|c|c|c|c|c|c|c|}
\hline \multicolumn{7}{|c|}{ Particle distribution proportion } \\
\hline Silt \% & Clay \% & Name & $\begin{array}{c}\text { Natural water content } \\
\%\end{array}$ & $\begin{array}{c}\text { Plastic limit } \\
\%\end{array}$ & $\begin{array}{l}\text { Liquidity } \\
\text { index }\end{array}$ & $\begin{array}{l}\text { Consistency } \\
\text { state }\end{array}$ \\
\hline 61.0 & 31.4 & Silty clay & 31.1 & 21.1 & 0.32 & Plastic \\
\hline \multicolumn{7}{|c|}{ Chemical properties } \\
\hline $\begin{array}{c}\text { The total soluble salt } \\
\%\end{array}$ & $\begin{array}{c}\mathrm{Na}^{+} \\
\mathrm{mmol} / \mathrm{kg}\end{array}$ & $\begin{array}{c}\mathrm{SO}_{4}^{2-} \\
\mathrm{mmol} / \mathrm{kg}\end{array}$ & $\begin{array}{c}\mathrm{HCO}_{3}^{-} \\
\mathrm{mmol} / \mathrm{kg}\end{array}$ & $\begin{array}{c}\mathrm{Cl}^{-} \\
\mathrm{mmol} / \mathrm{kg}\end{array}$ & Organic matter & $\mathrm{pH}$ \\
\hline 1.27 & 164.9 & 17.2 & 14.2 & 8.9 & $0.9 \%$ & 7.63 \\
\hline
\end{tabular}

is the highest. Under the guidance of technical code for building in saline soil regions (GB/T 50942-2014), it is also considered to be a carbonate-saline soil if $S=\frac{2 \mathrm{CO}_{3}^{2-}+\mathrm{HCO}_{3}^{-}}{\mathrm{Cl}^{-}+2 \mathrm{SO}_{4}^{2-}}>0.3$. The value of $\mathrm{S}$ for the studied soil is 0.31 ; thus, it is carbonate-saline soil.

\section{Experimental Scheme}

In the experiment, the samples were prepared in cylinders that were $5 \mathrm{~cm}$ in diameter and $20 \mathrm{~cm}$ in height. The experiments were carried out in an open system and closed system in order to study the water migration characteristics. The different freezing modes consisted of unipolar freezing and bipolar freezing. The different freezing temperatures were $-15^{\circ} \mathrm{C}$ and $-5^{\circ} \mathrm{C}$. In addition, a test of different temperature gradient directions was developed to investigate the soil water potential for water migration. Based on the experiments, the key points of this paper are as follows:

1) Characteristics of capillary water rise in unfrozen condition.

2) Characteristics of water migration in the condition of unipolar freezing.

3) Characteristics of water migration under the different freezing modes and different freezing temperatures.

4) Discuss the driving force of water migration for the studied soil and analyze the different characteristics under the different conditions.

Table 2 shows the details of the experimental programs.

\section{Experimental Installation}

The experiments are mainly based on the "rock and soil freezing-thaw trial and error imitating comprehensive experimental platform with ultracold condition," which was independently designed and invented by the department of geotechnical engineering of the construction engineering college in Jilin University.

The equipment consisted of two temperaturecontrolled boxes, which were marked as 1 and 2 . The height of the temperature boxes was $30 \mathrm{~cm}$. Each box had an independent attemperator. The temperature was controlled at the range of $-30 \sim+30^{\circ} \mathrm{C}$. The precision was $0.1^{\circ} \mathrm{C}$. Thermal insulation layers exist between the temperature-controlled boxes, which were made of insulating materials and were $20 \mathrm{~cm}$ thick. Several holes were drilled in the thermal insulation layers, and the diameter was $5 \mathrm{~cm}$. These holes were designed to carry out the experiments of water migration and salt transportation.

\section{Experimental Methods}

\section{Preparation of Soil Samples}

In the experiment, the soil samples were collected from a depth of $40 \mathrm{~cm}$ at the sampling point in Nong'an, western Jilin. First, the optimal water content was determined as $22 \%$ through the compaction test.

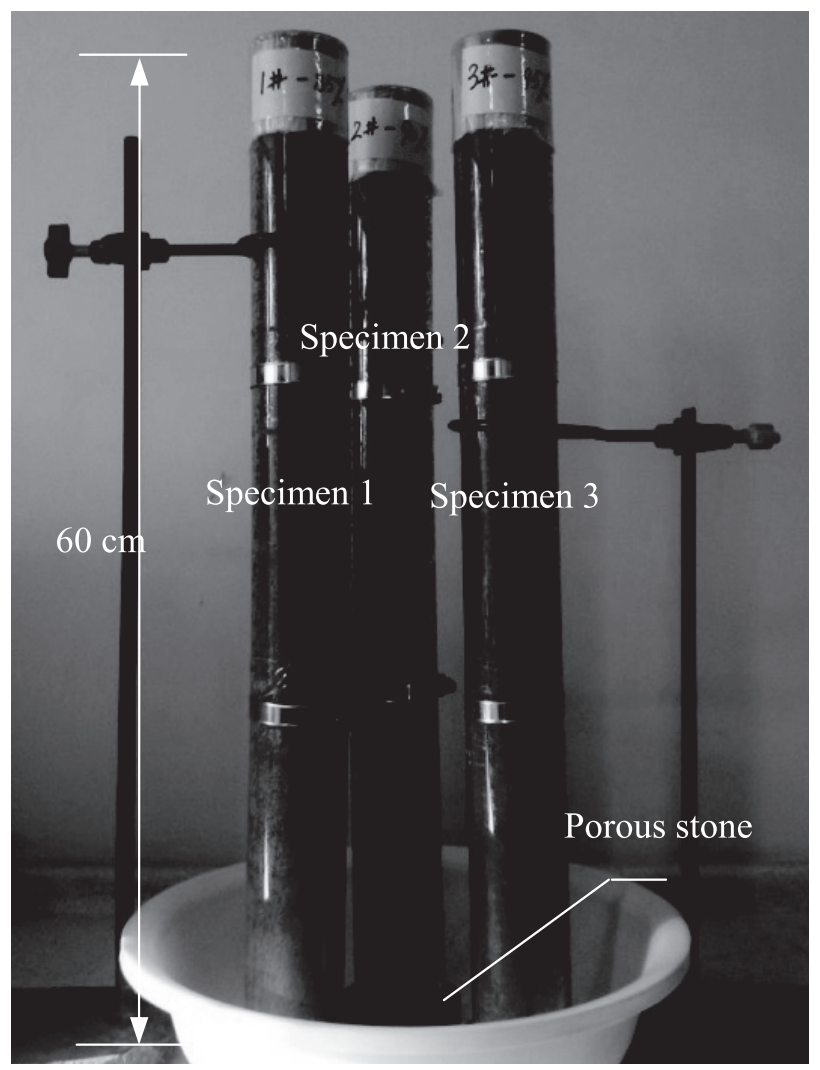

Fig. 3. Capillary water rise test. 


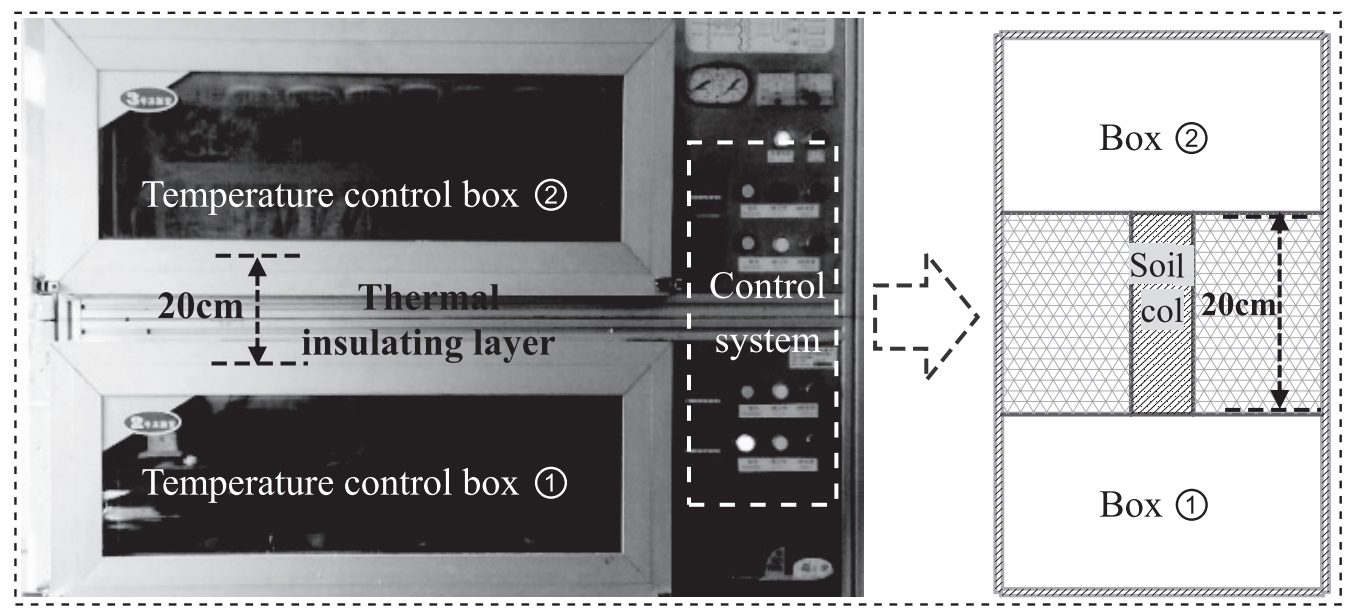

Fig. 4. Schematic diagram of the test apparatus and the studied soil sample.

The maximum dry density was $1.63 \mathrm{~g} / \mathrm{cm}^{3}$. Then, in accordance with the different compaction degrees, the designed dry densities were determined. All of the soil samples were mixed with distilled water so that the water content reached $22 \%$. Finally, the soil was compacted in the soil columns. The original salt content of the samples was maintained.

\section{Capillary Water Rise Test}

Following the results of the experimental programmes, the samples with optimal water content and different degrees of compaction were designed to be in $60 \mathrm{~cm}$ organic glass tubes. Under natural conditions, the colour of the columns changed due to the capillary water rise. During the test, the height of the capillary water was measured and recorded every hour. After $24 \mathrm{~h}$, the rate of capillary water rise became slow, and the height was recorded every 6 h. Fig. 3 shows the capillary water rise test.

\section{Water Migration Test}

First, install the samples. The thermal insulation layer between the temperature-controlled box 1 and 2 of the "rock and soil freezing-thaw trial and error imitating comprehensive experimental platform with ultracold condition" were applied. As shown in Fig. 4, the thermal insulation layer was $20 \mathrm{~cm}$ in height, and the samples were fixed vertically in the thermal insulation layer.

Second, adjust the experimental system. To study water migration under the freezing conditions in the open system, the water supply system was applied in temperature- controlled box 1 . The water supply system can provide water supplement at the bottom of the soil column so that the water of the samples can be supplied without stress. In contrast, the water supply system was not used in the closed system.

Third, control the temperature. Before the experiment, the samples were put into a temperaturecontrolled box, and the temperature was adjusted to $+10^{\circ} \mathrm{C}$ so that the initial temperature of the soil temperature was $+10^{\circ} \mathrm{C}$. In the experiment of unipolar freezing, the temperature of box 2 was set as a negative value, and the temperature of box 1 was kept $+10^{\circ} \mathrm{C}$ all the time. This ensured that the freezing could occur from the top to the bottom. In the bipolar freezing experiment, both of the temperature boxes 1 and 2 were adjusted to negative values, as needed. The details of the experimental programmes are listed in Table 2.

Table 2. Experimental scheme

\begin{tabular}{|c|c|c|c|c|c|}
\hline Experimental conditions & $\begin{array}{c}\text { Samples } \\
\text { number }\end{array}$ & $\begin{array}{c}\text { Degree of } \\
\text { compaction }\end{array}$ & $\begin{array}{c}\text { Temperature at } \\
\text { the top } /{ }^{\circ} \mathrm{C}\end{array}$ & $\begin{array}{c}\text { Temperature at } \\
\text { bottom } /{ }^{\circ} \mathrm{C}\end{array}$ & Annotation \\
\hline \multirow{4}{*}{$\begin{array}{c}\text { Capillary water rise test } \\
\text { (Unfrozen) }\end{array}$} & 1 & $85 \%$ & +10 & +10 & Open system, with water supply \\
\cline { 2 - 6 } & 2 & $90 \%$ & +10 & +10 & Open system, with water supply \\
\cline { 2 - 6 } & 4 & $95 \%$ & +10 & +10 & Open system, with water supply \\
\cline { 2 - 6 } & 5 & $85 \%$ & -15 & +10 & Closed system, freezing 5 days \\
\cline { 2 - 6 } & 6 & $85 \%$ & -15 & +10 & Open system, freezing 5 days \\
\cline { 2 - 6 } & 7 & $85 \%$ & -5 & -5 & Closed system, freezing 5 days \\
\hline \multirow{3}{*}{\begin{tabular}{c} 
Water migration test \\
\cline { 2 - 6 }
\end{tabular}} & 7 & & -15 & Closed system, freezing 5 days \\
\hline
\end{tabular}


Fourth, test the water content. After the freezing experiment, the column samples were immediately removed, and the soil column was cut into pieces at a thickness of $2 \mathrm{~cm}$. In total, 10 pieces of data for the water content were tested for each sample.

\section{Mathematical Theory}

Water migration in the soil is mainly caused by the unbalanced state in the soil-water system. The driving force of water transfer is defined as soil-water potential, which is composed of matric potential $\psi_{m}$, gravitational potential $\psi_{g}$, pressure potential $\psi_{p}$, and temperature potential $\psi_{T}$

$$
\psi=\psi_{m}+\psi_{g}+\psi_{T}+\psi_{p}
$$

For the unsaturated soil in natural conditions, water migration is mainly influenced by the matric potential and gravitational potential. In this paper, the shortrange adsorption is ignored, and the matric potential and gravitational potential contributes to the driving force in the capillary water rise test [28].

$$
\psi=\psi_{m}+\psi_{g}
$$

In freezing conditions, the temperature potential gradually formed, and the water transfer was also influenced by the temperature potential. The freezing tests show that the water always transfers toward the freezing parts under the temperature gradient. Ignoring the influence of matric potential, water migration for the studied soil that was subjected to freezing conditions was also influenced by the temperature gradient. The soil water potential can be expressed as:

$$
\psi=\psi_{T}+\psi_{p}+\psi_{g}
$$

The stress in the soil can be reflected through pore stress. In the freezing process, the water may freeze and become ice. Considering the phase change, the relationship between temperature and pressure can be expressed by the Clapeyron equation as [29]:

$$
\frac{u_{w}+p_{0}}{\rho_{w}}-\frac{u_{i}+p_{0}}{\rho_{i}}=L \ln \left(\frac{T}{T_{0}}\right)
$$

In freezing, the pore pressure is composed of pore water pressure and pore ice pressure, regardless of the pore gas pressure:

$$
u=\chi u_{w}+(1-\chi) u_{i}
$$

... where $\chi$ is a function of void ratio and the unfrozen water content; $\chi=\left(\theta_{u}(1+e) / e\right)^{1.5}$.

From the above, the temperature can be determined through the pore water pressure $u_{w}$, namely the temperature potential and the pressure potential can be comprehensively expressed by pore water pressure. On the basis of dimensional transformation, the soil water potential is determined in the form of water head

$$
\psi=z+\frac{u_{w}}{\rho_{w} g}
$$

...where $z$ is the water head for the gravitational potential and $u_{w}$ is the pore water pressure.

\section{Results and Discussion}

After considering the experimental system, freezing modes, and degrees of compaction, 7 samples were studied in the capillary water rise test and water migration test in freezing conditions. The results are compared and discussed in this section.

\section{Capillary Water Rise Test}

The capillarity of the water in the soil in the unfreezing natural condition was considered. Three soil columns of different compaction degrees, which were mixed with optimum water content, were fixed in the experimental flume. Each soil column had a porous stone at the bottom. At the beginning of the experiment, the water migrated upward, and the rising height of the capillary water tended to be steady after $48 \mathrm{~h}$. The final rising height of capillary water was measured at $3.2 \mathrm{~cm}, 3.0 \mathrm{~cm}$, and $2.7 \mathrm{~cm}$ after 30 days. Fig. 5 shows the experimental results. We conclude that all the capillary water rising height of the different compaction degrees were very small. Moreover, the final rising height of the capillary water was related to the compaction degree. The higher the compaction degree, the smaller the final rising height of the capillary water.

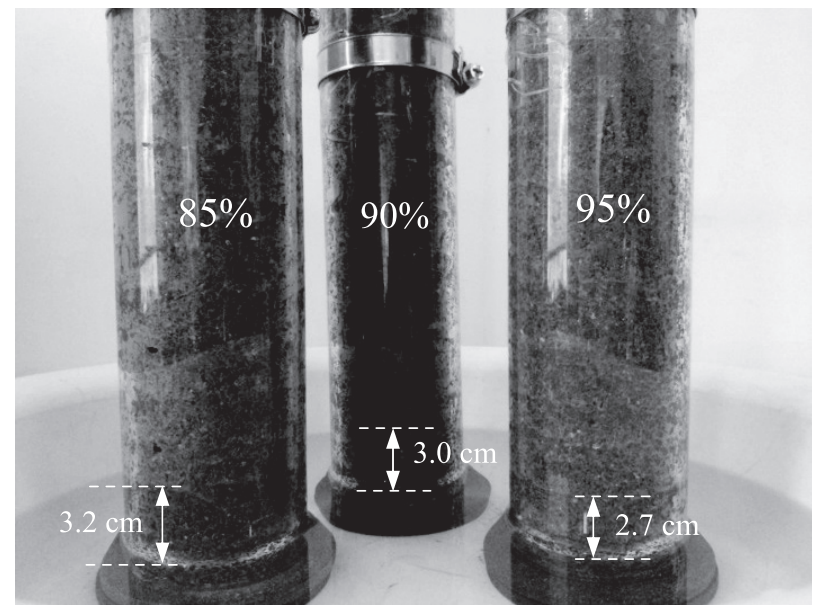

Fig. 5. Final height of capillary water rise. 


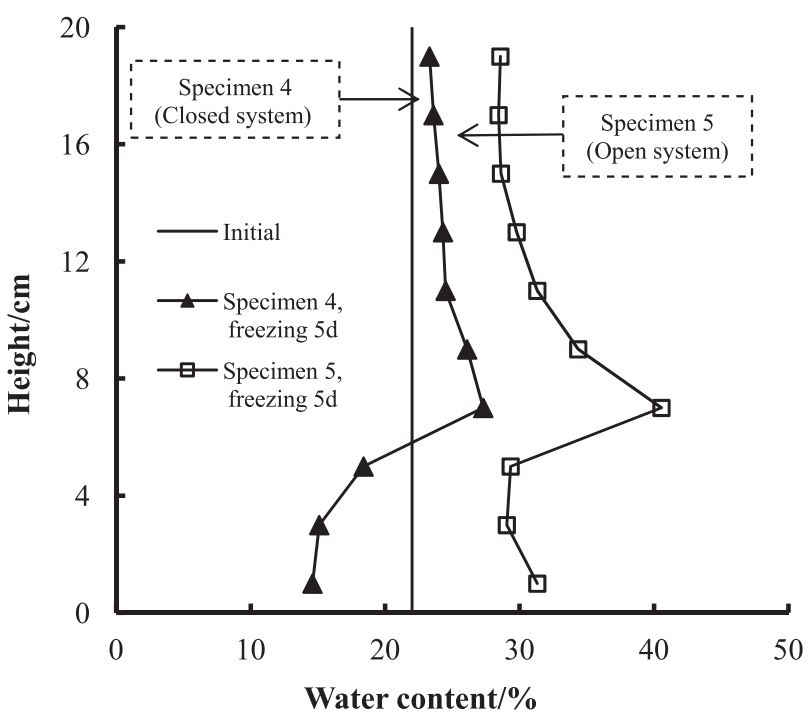

Fig. 6. Final height of capillary water rise.

\section{Water Migration Test under Freezing Conditions}

In the capillary water rise test, the rising height of capillary water was very small. Thus, to determine the influencing factors of water migration, 4 tests were carried out that considered the influence of the experimental system, freezing modes, and freezing temperature. Due to the result that all of the rising heights of the capillary water were small, compaction of $85 \%$ was selected in the water migration test under freezing conditions.

(1) Analysis of the water migration test in the open system and closed system. Under the unipolar freezing condition, the temperature of the top side was adjusted to $-15^{\circ} \mathrm{C}$, and the bottom temperature was set to $+10^{\circ} \mathrm{C}$.

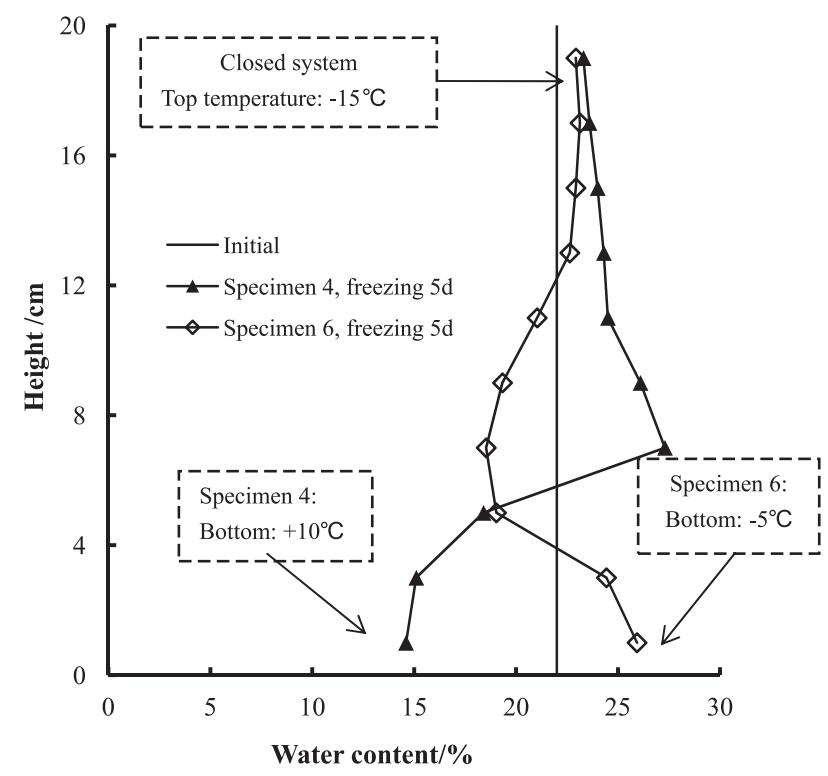

Fig. 7. Characteristics of water migration in the different freezing modes.
The experiment for the fourth sample was carried out in the closed system, while the experiment for the fifth sample was carried out in the open system in which the water supply system was applied at the bottom. Fig. 6 shows the distribution of water content along with the soil columns. The figure consists of three curves: one is the initial water content, and the other two curves are the water content distributions for the samples after 5 days. It is obvious that the distribution shapes for these two samples are similar. Both for the fourth and fifth samples, the water content increased above $7 \mathrm{~cm}$ and the water content reaches the peak value at $7 \mathrm{~cm}$. In the closed system, the water of the unfrozen zone migrates upward to the frozen zone constantly, resulting in the water content decreasing below $7 \mathrm{~cm}$. In the open system, there is a water supply system at the bottom, and the water migrates upward under the driving force resulting from the temperature potential [2]. Thus, the water content of the sample in the open system increases greatly, and the water content of the unfrozen also increased. At the position around 7 8 $\mathrm{cm}$, water gathered and water content increases signally. It is because after freeing for a long time, the temperature distribution along the soil column tends to be stable, the freezing front is around the position of $7 \mathrm{~cm}$, and the water in the unfrozen has plenty time to migrate to this position.

(2) Change of the distribution for the water content along the soil column in different freezing modes in the closed system. The same experimental system was selected to study the influence of the freezing modes: unipolar freezing and bipolar freezing. For the fourth sample, the top temperature was set at $-15^{\circ} \mathrm{C}$, and the bottom temperature was set at $+10^{\circ} \mathrm{C}$. For the sixth sample, the top temperature was adjusted to $-15^{\circ} \mathrm{C}$ and the bottom temperature was $-5^{\circ} \mathrm{C}$. Thus, there was unipolar freezing for the fourth sample and bipolar freezing for the sixth sample. Fig. 7 gives the water content distributions before the experiment and after freezing for 5 days. The distribution characteristics were different between these two samples. Under the temperature gradient, water transferred up to the frozen zone in the fourth sample. In the condition of bipolar freezing, water in the sixth sample migrated to both ends. As a result, the water content of the middle part decreased and the water content of both ends increased. There were two freezing fronts moving in the sixth sample. One moved from the top downward; the other from the bottom upward. Because the top temperature was lower than the bottom temperature, the upper freezing front moved faster than the other freezing front. Thus, the water in the soil column froze rapidly and had no time to migrate upward. In contrast, there was relatively more time for the water to migrate downward. Thus, the amount of water that migrated downward was more than that which migrated upward.

(3) In the closed system, the sample was subjected in the same bipolar freezing mode, but the temperature gradient direction was different. For the sixth sample, 


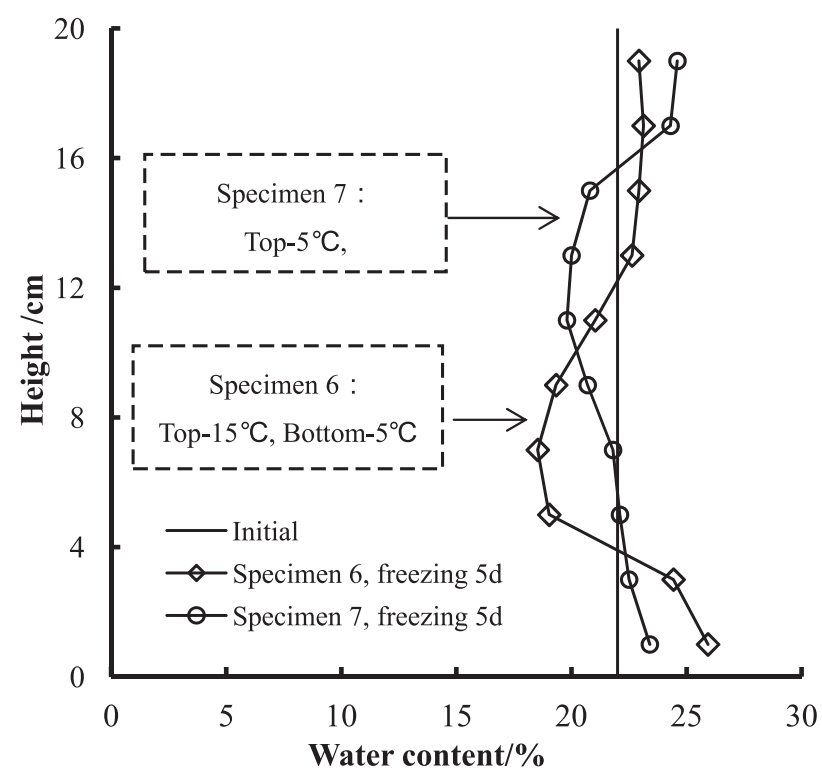

Fig. 8. Characteristics of water migration in different temperature gradient directions.

the top temperature was adjusted to $-15^{\circ} \mathrm{C}$, and the bottom temperature was $-5^{\circ} \mathrm{C}$. For the seventh sample, the top temperature was adjusted to $-5^{\circ} \mathrm{C}$, and the bottom temperature was $-15^{\circ} \mathrm{C}$. A comparison of the water content distribution after freezing 5 days between Samples 6 and 7 is shown in Fig. 8. The water content of both ends increased, and the water content in the middle parts decreased for both of the samples, indicating that the water transferred from the middle parts to both ends of the soil column in the process of bipolar freezing. In Sample 6 , the minimum value was at the $7 \mathrm{~cm}$ position, which was $18.5 \%$. In Sample 7, by contrast, the peak value appeared at the height of $12 \mathrm{~cm}$, where the water content decreased to $20 \%$. In addition, the amount of water that migrated downward is greater than that which

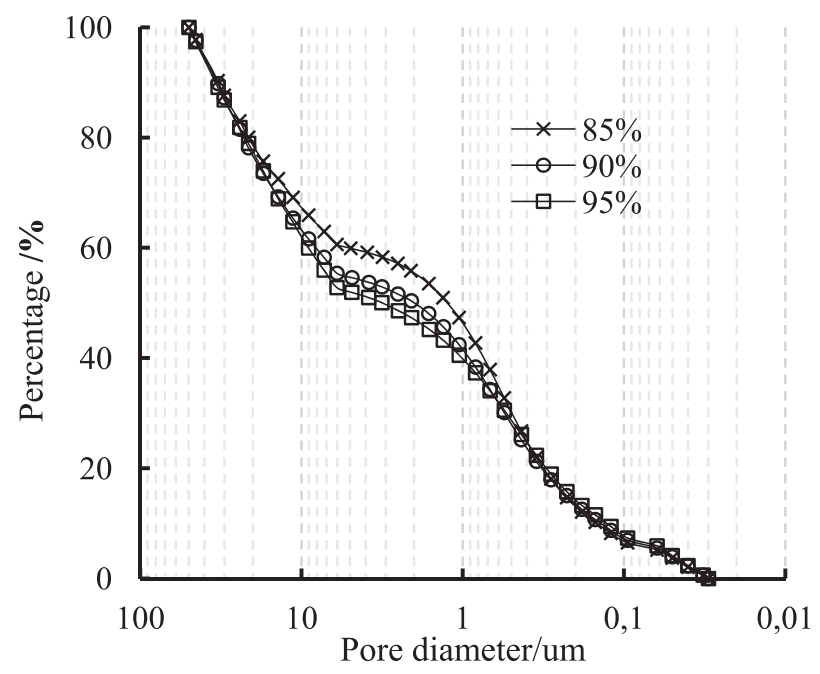

Fig. 9. Pore size distributions of soil samples with different compaction degrees. migrated upward in Sample 6, and the maximum value at the bottom reached $26 \%$. However, Sample 7 showed the opposite result and the maximum value at the top was $24.6 \%$. Considering that the gravitational potential is in the vertical direction, the experimental results indicate that gravitational potential affects the water migration slightly, and the water migration is mainly influenced by the driving force of the temperature potential.

\section{Analysis of Water Migration}

The pore size distributions of the samples with different compaction degrees were studied using the AUTO-PORE 9500 Mercury injection apparatus to understand the characteristics of water migration. Fig. 9 shows the pore size distribution curves of different samples with different degrees of compaction. To describe the characteristics of pore distribution, different views have been proposed to determine the size grades by summarizing and studying the pore size characteristics of different kinds of soil samples [2, 30]. According to the literature [31], the pores of the clayey soil samples can be divided into macro pore, large pore, mesopore, fine pore, and micropore. The boundaries of the pore sizes are $40 \mu \mathrm{m}, 4 \mu \mathrm{m}, 0.4 \mu \mathrm{m}$, and $0.04 \mu \mathrm{m}$, respectively. Informed by this rule, the pore distributions of the samples were divided, as shown in Fig. 10.

The results indicate that the pore size distribution characteristics of the samples at three degrees of compaction are similar. The mesopore, fine pore, and especially the large pore, have a high content. A comparison of the three different degrees of compactions, the proportions of fine pore, micropore, and macro pores show that they are similar. As the degree of compaction increases, the proportion of mesopore increases, but the proportion of large pores and macro pores decrease. This is because the large pores and macro pores are compacted in the compaction process, and the range of influence is $0.4 \sim 4 \mu \mathrm{m}$.

As we know, the capillary size for the soil is mainly in the range of $0.002 \sim 0.5 \mathrm{~mm}$. Thus, it can be determined that the proportion of the capillary pores in this range for the compaction degrees of $85 \%, 90 \%$, and $95 \%$ are $48.8 \%, 46.1 \%$, and $41.0 \%$, respectively. Due to these characteristics of the pore size distributions,

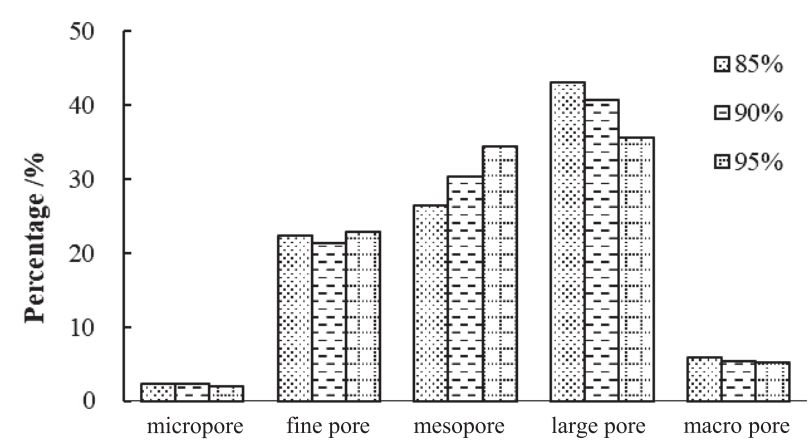

Fig. 10. Proportions of the different size pores. 
the final height of capillary water for the sample with $85 \%$ compaction degree is relatively higher.

The capillary water rise test was carried out in the open system with water supplied at the bottom. Under the effect of soil-water potential, capillary water rises through the soil pores. Moreover, the mercury injection test showed that the proportions of capillary pores of all the samples were over $40 \%$. Theoretically, the rising heights of the capillary water should be obvious. However, the experiments show low heights, indicating that the water at the bottom did not rise through the capillary pores. Thus, under the effects of matric potential and gravitational potential, capillary water rises a little, and the matric potential and gravitational potential have small effects on the height of capillary rise for the studied soil. As a result of the analysis, we conclude that the results are related to the soil texture and properties, which are mainly influenced by two properties. First, the proportion of clay grains is high, at more than $30 \%$. The proportion of organic matter is more than $0.9 \%$. Since the proportions of organic matter and clay grains are small in size, their specific surface area is high, and the surface energy is also high. As a result, thick, diffused double layers of the grains are more easily formed, and the voids among the particles become small or are even blocked. Second, the soluble salt test shows that the salt content is high, especially for $\mathrm{Na}^{+}$. When the soil is subjected to water, $\mathrm{Na}^{+}$is dissolved in the water. When the clay particle contacts the water, the high valence cations absorbed on the surface of the particles are displaced by $\mathrm{Na}^{+}$, as follows:

$$
R^{n+}\left[\begin{array}{c}
\text { Soil } \\
\text { grain }
\end{array}\right]+n N a^{+}=\begin{gathered}
N a^{+} \\
N a_{n}^{+}
\end{gathered}\left[\begin{array}{c}
\text { Soil } \\
\text { grain }
\end{array}\right]+R^{n+}
$$

Under a certain value of the thermodynamic potential, $\varepsilon$, if the content of $\mathrm{Na}^{+}$in the diffused double layer is high, the attraction of the clay particle to the single action in the diffused double layer is low. Thus, the distance between action and the clay particle increases. Then, the electrokinetic potentialincreases, and the diffused double layer becomes thicker. As a result, the overlapping water film is formed and absorbed around the soil particles. The water film becomes thicker, and the capillary pores among the soil particles become smaller or are blocked when the thickness of the water film is over a certain value. Fig. 11 shows the schematic diagram. Due to this process, the rising height of capillary water for the studied soil was low.

The water migration test under freezing conditions indicated that the water migrates under the effect of freezing. As discussed in the capillary water rising test, the bound water film was thick, which blocked the capillary pores, and the capillary water could not rise. As we know, there are different kinds of water that exist, including gravity water, capillary water, bound water, crystal water, and others. The freezing order of the water in the soil is gravity water $\rightarrow$ capillary water $\rightarrow$ bound water [15]. Thus, during freezing, the capillary water will first turn to ice, and in this process, the upward migration of unfrozen water is mainly in the form of bound water. Therefore, it is the bound water that migrates through the overlapping water film under the temperature gradient. Comparing the unipolar freezing in a closed system with that in an open system, the water migration has the same rule, which is that water always migrates from the unfrozen zone to the frozen zone. In the closed system, heat transfers quickly, and the temperature near the top decreases rapidly to the freezing point, and the water in the unfrozen zone does not have enough time to migrate upwards. Thus, the increased amount of water content of Sample 4 is small. With the increasing freezing time, the distribution of temperature along the soil column tends to be stable, and the freezing front is approximately at the $7 \mathrm{~cm}$ position. Water has enough time to migrate to this position; thus, the water content at this position reaches a peak value of $27.3 \%$. The water content below this position obviously decreases. This is because this part is unfrozen all the time, and the water in this part has migrated up to the frozen zone. In the open system, the water content distribution shape of Sample 5 is similar to that of

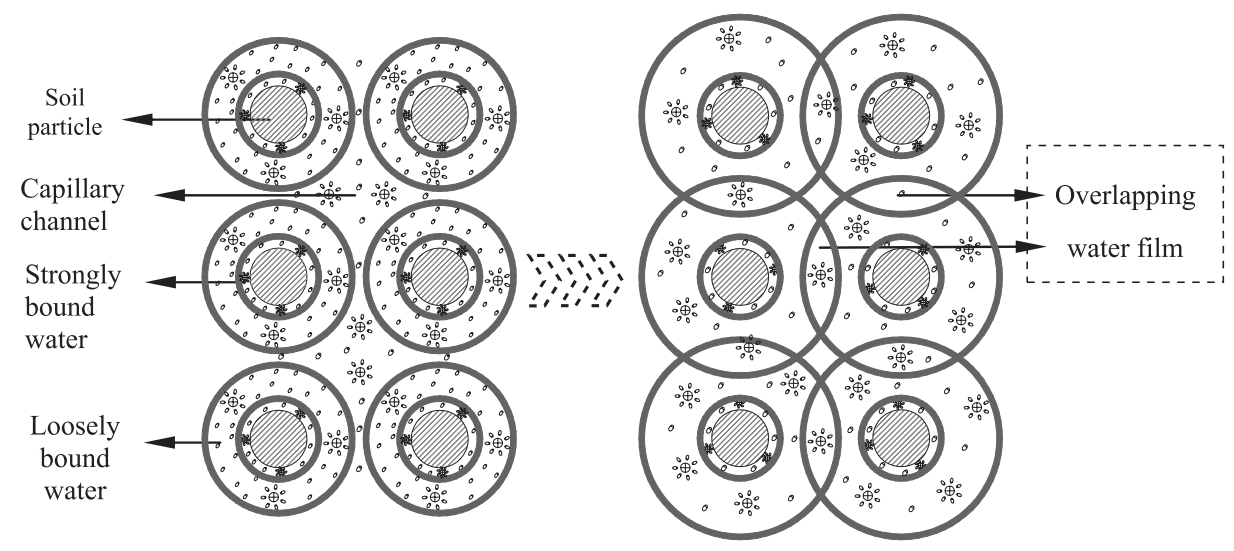

Fig. 11. Diffused double layer becomes thick when clay particles are subjected to water. 
Sample 4, but the values are higher. The water content value of the frozen zone is approximately $30 \%$. It reaches the maximum value at the $7 \mathrm{~cm}$ position, and the peak value is $40.5 \%$. Due to the water supplement at the bottom, the unfrozen water constantly transfers to the frozen zone through the overlapping water film.

Compared to the unipolar freezing and bipolar freezing in the closed system, water always transfers toward the freezing part. After freezing for 5 days, the $7 \mathrm{~cm}$ position was the boundary between the frozen and unfrozen zone of Sample 4. The water content of the frozen zone increased but decreased in the unfrozen zone. The maximum value was approximately at the $7 \mathrm{~cm}$ height. Bipolar freezing was developed in the closed system; the bottom temperature was $-5^{\circ} \mathrm{C}$ and the top temperature was $-15^{\circ} \mathrm{C}$. In the freezing process, the bound water migrated to both ends. Along the soil column, the water content at the height of $5 \sim 11 \mathrm{~cm}$ decreased, and it reached the minimum value of $18.5 \%$ at $7 \mathrm{~cm}$. Close to the bottom, the maximum water content was $26 \%$. In addition, the increased amount of water content near the top was smaller than at the bottom because the top temperature was lower than the bottom, and the heat transferred rapidly close to the top. During the freezing process of the top, the unfrozen water had no time to migrate upwards, whereas the heat at the bottom transferred relatively slowly, and the unfrozen water in the soil had more time to migrate to the bottom. Thus, from the above results, we conclude that the water migration under freezing conditions is the migration of bound water, and the driving force consists of gravitational potential and temperature-press potential.

In the closed system, both Samples 6 and 7 were under bipolar freezing conditions. From Fig. 8, we see that these two curves are distributed symmetrically. No matter what the temperature gradient direction is, the water content near the side of $-5^{\circ} \mathrm{C}$ is higher than that near the side of $-15^{\circ} \mathrm{C}$. Additionally, the minimum value is always $7 \sim 8 \mathrm{~cm}$ distant from the side of $-5^{\circ} \mathrm{C}$ because this side's temperature decreased slowly, and the water had more time to transfer. When the temperature gradient direction changed, the water migration was dominantly influenced by temperature. Thus, during the freezing process, temperature plays a decisive role in water migration but is little influenced by the gravitational potential.

\section{Conclusions}

1) The capillary water rise tests for the studied soil indicate that the final height of the capillary water is low, at approximately $3 \mathrm{~cm}$. Additionally, the final height of capillary water is related to the compaction degrees. The higher the compaction degree, the lower the height of capillary water. The low height of capillary water is related to the high content of $\mathrm{Na}^{+}$. The thick bound water film leads to the formation of an overlapping water film, which blocks the capillary pores.

2) The experiments indicate that water migration in the study area is caused by freezing. In the freezing process, the bound water transfers toward the freezing parts through the overlapping water film. In this cold region, the bound water migration in the freezing condition has a great effect on salt transport. This paper provides references on further studies of water-salt migration and the secondary salinization for the study area.

3) In the freezing process, water migration is affected by the temperature potential and gravitational potential. The lower the temperature of the cold side, the smaller the migration amount. Since the temperature changes too quickly if the temperature of the cold side is very low, the water does not have enough time to migrate.

4) For the soil in western Jilin, the soil water potential is the driving force during freezing. The temperature potential plays a decisive role on the bound water migration, and the gravitational potential and matric potential have little effect.

\section{Acknowledgements}

The author is grateful for the financial support for this study from the State Key Program of the National Natural Science Foundation of China (grant No. 41430642), the Special Fund for Major Scientific Instruments of the National Natural Science Foundation of China (grant No. 41627801), the National Natural Science Foundation of China (grant No. 41372267), and the Graduate Innovation Fund of Jilin University (grant No. 2017067).

\section{Conflict of Interest}

The authors declare no conflict of interest.

\section{Reference}

1. ZHANG X., WANG Q., LI P., WANG R. Research on Soil Dispersion of Qian'an Soil Forest. Journal of Northeastern University (Natural Science), 36 (11), 1643, 2015.

2. ZHANG X., WANG Q., WANG G., WANG W., CHEN H., ZHANG Z. A Study on the Coupled Model of Hydrothermal-Salt for Saturated Freezing Salinized Soil. Mathematical Problems in Engineering, 2, 1, 2017.

3. ZHANG X., WANG Q., HUO Z., YU T., WANG G., LIU T., WANG, W. Prediction of Frost-Heaving Behavior of Saline Soil in Western Jilin Province, China, by Neural Network Methods. Mathematical Problems in Engineering, 4, 1, 2017.

4. WANG C.Y., ZHI-JIE W.U., SHI, Y.L., WANG R.Y. The Resource of Saline Soil in the Northeast China. Chinese Journal of Soil Science, 35 (5), 643, 2004. 
5. INSTITUTE OF FORESTRY AND SOIL SCIENCES, C.A.S. Soil in northeast china. Science Press: Beijing, China, 220, 1980.

6. JILIN PROVINCIAL SOIL AND FERTILIZER STATION, C. Jilin Soil. Agricultural Press: Beijing, China, 195, 1998

7. LIU H.Q., JIA-WEI X.U., XIU-QIN W.U. Present situation and tendency of saline-alkali soil in west Jilin Province. Journal of Geographical Sciences, 11 (3), 321, 2001.

8. XIAO Y., HUANG Z., YANG F., LU X. The Dynamics of Soil Moisture and Salinity after Using Saline Water Freezing-Melting Combined with Flue Gas Desulfurization Gypsum. Polish Journal of Environmental Studies, 23 (5), 1763, 2014

9. FABIÁN F.-L., REYNA M.-C., LUC D. Do Application Rates of Wastewater Sewage Sludge Affect the Removal of PAHs from Alkaline Saline Soil?. Polish Journal of Environmental Studies, 25 (6), 2367, 2016.

10. ZHAN, C., LI L., LOCKINGTON D. Numerical study of evaporation-induced salt accumulation and precipitation in bare saline soils: Mechanism and feedback. Water Resources Research, 50 (10), 8084, 2014.

11. BAO S., WANG Q., BAO X., WANG Z. Characters of Saline-alkali Soil in Western Jilin and biological Treatment. Journal of Pure \& Applied Microbiology, 7, 809, 2013.

12. LAI Y., PEI W., ZHANG M., ZHO J. Study on theory model of hydro-thermal-mechanical interaction process in saturated freezing silty soil. International Journal of Heat and Mass Transfer, 78, 805, 2014.

13. WU D., LAI Y., ZHANG M. Thermo-hydro-saltmechanical coupled model for saturated porous media based on crystallization kinetics. Cold Regions Science and Technology, 133, 94, 2017.

14. ZHANG Y., MICHALOWSKI R.L. Thermal-hydromechanical analysis of frost heave and thaw settlement. Journal of Geotechnical and Geoenvironmental Engineering, 141 (7), 04015027, 2015.

15. XU X., WANG J., ZHANG L. Physics of frozen soil. Science Publish House, Beijing, China. ISBN, 2010.

16. ZHOU J., WEI C., LI D., WEI H. A moving-pump model for water migration in unsaturated freezing soil. Cold Regions Science and Technology, 104, 14, 2014.

17. GRAN M., CARRERA J., OLIVELLA S., SAALTINK M.W. Modeling evaporation processes in a saline soil from saturation to oven dry conditions. Hydrology and Earth System Sciences, 15 (7), 2077, 2011.

18. IBRAHIMI M.K., MIYAZAKI T., NISHIMURA T., IMOTO H. Contribution of shallow groundwater rapid fluctuation to soil salinization under arid and semiarid climate. Arabian Journal of Geosciences, 7 (9), 3901, 2014.
19. MIAO C., CHEN J., ZHENG X., ZHANG Y., XU Y., DU Q. Soil Water and Phreatic Evaporation in Shallow Groundwater during a Freeze-Thaw Period. Water, 9 (6), 396, 2017.

20. LI Y., WANG Q., ZHAO A.P. Influence of Basic Properties of Seasonally Frozen Soil on Moisture Movement in Changchun Area. Journal of Jilin University, 38 (2), 279, 2008.

21. WANG W. A study on the Water Content Migration and Characteristics of Frost Heaving of Saline Soil in the Western of Jilin Province. Jilin University. PhD thesis. 2011.

22. ZHAO G., TAO X., LIU B. Experimental study on water migration in undisturbed soil during freezing and thawing process. Chinese Journal of Geotechnical Engineering, 12, 028, 2009.

23. CAI J., YU B. A Discussion of the Effect of Tortuosity on the Capillary Imbibition in Porous Media. Transport in Porous Media, 89 (2), 251, 2011.

24. ZHAO Y., SI B., HE H., XU J., PETH S., HORN R. Modeling of Coupled Water and Heat Transfer in Freezing and Thawing Soils, Inner Mongolia. Water, 8 (10), 424, 2016.

25. HIRD R., BOLTON M.D. Migration of sodium chloride in dry porous materials. Proceedings of the Royal Society A Mathematical Physical \& Engineering Sciences, 472 (2186), 20150710, 2016.

26. BAO S. Frost heaving Characteristic and PFC-3D Numerical Analysis of Saline Soil in Western Jilin Province. Jilin University. PhD thesis. 2015.

27. HUO Z. Study on Frost Heaving Behavior of the Carbonate-Saline soil in Nong'an, Jilin Province. Jilin University. PhD thesis. 2016.

28. LIU Z., SUN Y., YU X.B. Theoretical basis for modeling porous geomaterials under frost actions: A review. Soil Science Society of America Journal, 76 (2), 313, 2012.

29. THOMAS H.R., CLEALL P., LI Y.C., HARRIS C., KERN-LUETSCHG M. Modelling of cryogenic processes in permafrost and seasonally frozen soils. Géotechnique, 59 (59), 173, 2009.

30. LEI X. Pore types and collapsibility of loess soils in China. Science in China (Series B), 12 (1), 309, 1987.

31. QING W., JIANPING W. A study on fractal of porosity in the soils. Chinese Journal of Geotechnical EngineeringChinese edition, 22 (4), 496, 2000. 
